\title{
Development and Validation of A HPLC-UV Method for Dissolution Testing of Ciclosporin: Its Application to The Measurement of Brand and Generic Versions from Different Countries
}

\author{
Badr Aljohani ${ }^{1,2^{*}}$, Faisal Alotaibi $\mathrm{F}^{\mathbf{1}, 3}$, Essam Ghazaly ${ }^{4}$, Jaber Al Jaber ${ }^{5}$, David Perrett ${ }^{1}$ and Atholl Johnston ${ }^{1}$ \\ ${ }^{1}$ William Harvey Research Institute, Queen Mary University of London, Charterhouse Square, London, EC1M6BQ, UK \\ ${ }^{2}$ King Abdullah International Medical Research Centre, Ministry of National Guard Health Affairs (MNGHA), Riyadh, KSA, Saudi Arabia \\ ${ }^{3}$ College of Pharmacy, University of Shaqra, Al Dawadmi, Saudi Arabia \\ ${ }^{4}$ Centre for Haemato-Oncology, Barts Cancer Institute, Queen Mary University of London, Charterhouse Square, London, EC1M6BQ, UK \\ ${ }^{5}$ Department of Pharmacology and toxicology, Faculty of Medicine, University of Kuwait, Kuwait
}

\begin{abstract}
Ciclosporin is used as an immunosuppressant in post-organ transplantation. Recently, many questions have been raised about using generic substitutes, especially with narrow therapeutic index drugs (NTIDs). In this study, a simple high-performance liquid chromatography (HPLC) method was developed, validated and applied to detection ciclosporin in dissolution testing. Seven ciclosporin products (gelatin capsules) were included in this study, obtained from Columbia (C), Egypt (E), India (I), Jordan (J), Pakistan (P), Saudi Arabia (S), and Turkey (T). The dissolution test was done for all capsules. The Conditions were as follows: $500 \mathrm{ml}$ deionized water as the medium in apparatus 2 (Pharmatest, Germany), temperature $37.5 \pm 0.5^{\circ} \mathrm{C} ; 50 \mathrm{rev} / \mathrm{min}$, sampling times were $5,10,15,30,60$ and $90 \mathrm{~min}$ with $5 \mathrm{ml}$ for each sample. HPLC separation was done by a C18 column, $5 \mu \mathrm{m},(4.6 \times 250 \mathrm{~mm}$, ACE 5) held at $50 \pm$ $0.3^{\circ} \mathrm{C}$. Analytes were isocratically eluted at $0.7 \mathrm{ml} / \mathrm{min}$ with acetonitrile and water $(70+30 \%)$ and $0.03 \%$ trifluoroacetic acid, over the 25-min run time. The intra-day and inter-day imprecision for ciclosporin across the standard range was $<5 \%$ and $<4 \%$, respectively. The accuracy of the assay was within $\pm 13 \%$ of the true value at standard curve concentrations range from 0.1 to $2 \mathrm{mg} / \mathrm{ml}$ of ciclosporin. The lower and the upper limit of detection were $0.001 \mathrm{mg} /$ $\mathrm{ml}$ and $2 \mathrm{mg} / \mathrm{ml}$ of ciclosporin, respectively. All brands (S, T, P, J, E) and one generic (C) showed more than $80 \%$ of ciclosporin after $90 \mathrm{~min}(90.3,100,90.4,82.7,81.4$ and $90.6 \%)$ respectively. One generic (I), showed less than the minimum percentage of labeled amount, $69.1 \%$. Relative to the brand $(T)$, statistical analysis showed significant differences $(P<0.0001)$ of the mean percentage content between brand and generic. The $95 \%$ confidence interval range for the brands (E, J, P, and S) was (72.2-91.8), (73.4-93.3), (80.2-101.9), and (80.1-101.8), respectively, and (80.3-102.1), and (61.3-77.9) for the generic $(C)$ and $(I)$ respectively. Based on these results, we conclude that some of the ciclosporin preparations do not contain the exact mass labeled and the majority contained as yet unidentified impurities.
\end{abstract}

Keywords: Ciclosporin; Brand and generic; High performance liquid chromatography (HPLC); Dissolution testing; Narrow therapeutic index drugs (NTIDs); Immunosuppressant

\section{Introduction}

In the last few years, many clinical questions have been raised about using generic substitutes, especially those for narrow therapeutic index drugs (NTIDs) such as ciclosporin. The patient should be closely monitored [1].

Ciclosporin (cyclosporine A, ciclosporin A, cyclosporin A, CyA) is a lipophilic cyclic undecapeptide compound formed by a soil fungus called Tolypocladiuminflatum Gams [2]. It was discovered by Sandoz of Basel, Switzerland in the 1970s [3], as synthetic or semi-synthetic [4]. It has been widely used since 1978 after organ or tissue transplant to prevent rejection [5,6]. For auto-immune diseases such as severe rheumatoid arthritis and psoriasis, ciclosporin can be used (Figure 1) [7].

Ciclosporin can be given intravenously or orally, as a solution or soft gelatine capsule. The capsules contain several ingredients such as Corn oil-mono-di-triglycerides [8].

High-performance liquid chromatography (HPLC) is an excellent technique for measuring average drug content in tablets and capsules. It can be used for therapeutic drug monitoring (TDM) when suitable detectors such as a mass spectrometer are used. The advantages of HPLC-mass spectrometry are high sensitivity, specificity, small sample requirements, minimal sample preparation, rapid throughput, and simultaneous measurement for the drug and its impurities. However, using the current assay, it is impossible to know if unknown impurities have interfered with ciclosporine. HPLC with ultraviolet/fluorescent detection is also a good method to quantify and analyse the content of ciclosporin capsules. Like other peptides, ciclosporin can be measured by HPLC at relatively low UV absorbance wavelengths and this is considered as a gold standard for its measurement [9-11].

There have been various methods to measure the drug contents in ciclosporin capsules. Some of them used to cut ciclosporin capsules and dissolving them before subjecting it to analytical HPLC system [12]. Other suggests cutting ciclosporin capsule and obtaining the contents and dissolves a known volume in the mobile phase before quantifying

${ }^{*}$ Corresponding author: Badr Aljohani, Clinical Pharmacology, B.Pharm, M.Sc, Ph.D., MRSC, King Abdullah International Medical Research Centre, Ministry of National Guard Health Affairs (MNGHA), Riyadh, KSA, Saudi Arabia, Tel: +44 207 882 2101; Fax: +44 208793 8397; E-mail: b.aljohani@qmul.ac.uk

Received July 22, 2017; Accepted September 11, 2017; Published September 19, 2017

Citation: Aljohani B, Alotaibi F, Ghazaly E, Jaber JA, Perrett D, et al. (2017) Development and Validation of A HPLC-UV Method for Dissolution Testing of Ciclosporin: Its Application to The Measurement of Brand and Generic Versions from Different Countries. J Bioequiv Availab 9: 509-515. doi: 10.4172/jbb.1000354

Copyright: @ 2017 Aljohani B, et al. This is an open-access article distributed under the terms of the Creative Commons Attribution License, which permits unrestricted use, distribution, and reproduction in any medium, provided the original author and source are credited. 
<smiles>C/C=C/CC(C)C(O)C(C(=O)NC(CC)C(=O)N(C)CC(=O)N(C)C(CC(C)C)C(=O)NC(C(=O)N(C)C(CC(C)C)C(=O)NC(C)C(=O)NC(C)C(=O)N(C)C(CC(C)C)C(=O)N(C)C(CC(C)C)C(=O)N(C)C(C(=O)N(C)C(CC(C)C)C(C)C)C(C)C)C(C)C)N(C)C(=O)C(CC(C)C)N(C)C(=O)C(C)C</smiles>

Figure 1: The chemical structure of ciclosporin (Drawan by Aljohani, 2014, using ACD/Labs 2012, version 14.01, build 65894).

using HPLC [12]. According to the United States Pharmacopeia, 2008 [13], they recommend to cut about 20 capsules and extract the contents with the aid of alcohol and make up a known solution in a volumetric flask with ethanol. Then dilute this stock to obtain a concentration of 1 $\mathrm{mg} / \mathrm{mL}$. This is used to determined ciclosporin in capsules. The other method is to obtain the contents of a capsule by aspirate, using a syringe and preparing from the obtained stock. Therefore, a dissolution method of rupturing the capsule in medium and then measuring the content of ciclosporin in the dissolution medium would give rise to more reproducible results. Several methods have been developed to measure ciclosporin in biological matrices $[14,15]$. However, our methos are tailored for quantification of ciclopsorin in dissolution testing.

Ciclsoporin is classified as a BCS IV because of its low solubility and poor permeability [16]. However, the dissolution test is carried out under standard conditions described in the FDA guidelines.

\section{Material and Methods}

\section{General chemicals}

Cyclosporin A (lot no. BCBD2418V, catalogue number: 30024-100 mg, 98.5\% Purity) for calibrator and control samples preparation and HPLC-grades solvent were obtained from Sigma-Aldrich, Poole, UK. HPLC-grade deionised water at a purity of $18.2 \mathrm{M} \Omega \mathrm{cm}$ was obtained from an ultra-water system (PURELAB ${ }^{\circ}$ ULTRA), Marlow, United Kingdom.

\section{Equipment}

PT-DT 70 dissolution tester and $20 \mu \mathrm{m}$ Poroplast Filter Element were from PharmaTest, Hainburg, Germany. High-quality electronic instrument: Sartorius (R 160 P) Electronic Semi-Microbalance, Sartorius Stedim, Surrey, United Kingdom. Ultra-water system (PURELAB'ULTRA) for deionised water, ELGA, UK. HPLC system Jasco UV- 975 intelligent UV-VIS with Jasco AS-950 intelligent sampler injector, two Jasco PU-980 intelligent HPLC pumps and Jasco DG2080-53 3 lines degasser. Jones Chromatography (Column Heater) Model 7990. The HPLC experiment was carried out with a UV detection wavelength of $210 \mathrm{~nm}$. The separation was carried out using a reversed phase $\mathrm{C} 18$ column, $5 \mu \mathrm{m},(125 \times 4.6 \mathrm{~mm}$, ACE 5, part number: ACE-121-
1246) Advanced Chromatography Technologies, Aberdeen, AB25 1HF, Scotland. JENWAY spectrophotometer, Ultra-Violet/Visible, Model $6715 \mathrm{UV} / \mathrm{Vis}$. The column temperature was maintained at $50^{\circ} \mathrm{C}$ and the injection volume was $20 \mu \mathrm{L}$. The analytes were eluted by isocratic elution at a flow rate of $0.7 \mathrm{~mL} / \mathrm{min}$ with acetonitrile and water $(70: 30 \%, \mathrm{v} / \mathrm{v})$ and $0.03 \%$, v/v trifluoroacetic acid, over $25 \mathrm{~min}$. The HPLC control data acquisition was by Chromatography Data System version 1.8.6.1 from JASCO Chrom Pass.

\section{Collection of drug samples}

All brand samples manufactured by Novartis in Switzerland T (100 $\mathrm{mg}), \mathrm{S}(100 \mathrm{mg}), \mathrm{E}(50 \mathrm{mg}), \mathrm{J}(50 \mathrm{mg})$, and $\mathrm{P}(100 \mathrm{mg})$, then repackaged in the importing country. Both generics $\mathrm{C}(100 \mathrm{mg})$ and $\mathrm{I}(100 \mathrm{mg})$ were manufactured in India. All samples were obtained from a commercial pharmacy, except one sample (S) was from a government hospital.

\section{Extraction by dissolution}

A dissolution method to analyse ciclosporin capsules were obtained from US Pharmacopeia 2008 [13], (USP-31) requirements such as rupturing time within $15 \mathrm{~min}$.

Seven ciclosporin products were included in this study. All products were stored according to the conditions labelled on the package. Each capsule was weighed to check the dosage uniformity. Dissolution test carried out under the following condition: Temp: $37.5^{\circ} \mathrm{C} \pm 0.5,500 \mathrm{~mL}$ deionized water used as a medium, the paddle apparatus (Apparatus 2):50 rpm, sampling time at $(5,10,15,30,60$, and $90 \mathrm{~min}$ ), with $5 \mathrm{~mL}$ volume for each sample. The samples were filtered using $20 \mu \mathrm{m}$ filters.

\section{HPLC experimental method development}

Identification of the $\lambda_{\text {max }}$ for ciclosporin measurement: A standard ciclosporin solution of $2 \mathrm{mg} / \mathrm{mL}$ was used to detect the $\lambda_{\max }$. The spectrum was compared to an acetonitrile blank which was used as a base line. The scan range of the spectrophotometer was set from $190 \mathrm{~nm}$ to $400 \mathrm{~nm}$ to detect maximum absorbance for ciclosporin throughout this range.

\section{Selection of columns}

Various C18 columns were tested to get a good separation of 
Citation: Aljohani B, Alotaibi F, Ghazaly E, Jaber JA, Perrett D, et al. (2017) Development and Validation of A HPLC-UV Method for Dissolution Testing of Ciclosporin: Its Application to The Measurement of Brand and Generic Versions from Different Countries. J Bioequiv Availab 9: 509-515. doi: 10.4172/jbb.1000354

ciclosporin in the HPLC method. The ACE 5 column showed the best results. All subsequent development was undertaken on this column.

\section{Optimisation of temperature for separation of ciclosporin}

Based on literature review and the US Pharmacopeia, different temperatures to heat the column were investigated, at 25,50 , and $75^{\circ} \mathrm{C}$ The best resolution obtained at $50^{\circ} \mathrm{C}$

\section{Optimisation of flow rate}

Different flow rates at $0.7,1$, and $1.2 \mathrm{~mL} / \mathrm{min}$ used to obtain best resolution and peak shape, the best resolution was found at $0.7 \mathrm{~mL} /$ min.

\section{Preparation of stock, calibration solutions and control samples}

Ciclosporin stock solution $(2 \mathrm{mg} / \mathrm{mL})$ was prepared in the mobile phase and stored at $20^{\circ} \mathrm{C}$. The ciclosporin calibration standards were freshly prepared at the time of the experiment. Eight concentrations of ciclosporin $(0.1,0.2,0.4,0.6,0.8,1,1.5$ and $2 \mathrm{mg} / \mathrm{mL})$ were prepared in mobile phase.

\section{Calibration and linearity}

Calibration standards $(0.1-2 \mathrm{mg} / \mathrm{mL})$ were injected into the HPLC system. The integrated peak areas of the ciclosporin were recorded. Linear regression of the standards was done using Microsoft Excel 2010 , by plotting the peak area of ciclosporin against the ciclosporin concentration of the standards. The linearity was checked by calculating the $\mathrm{r} 2$ value using least-square linear regression analysis.

\section{Method sensitivity}

The upper limit of detection is given by the point where the detector response deviates by $1 \%$ from expected linear response.

\section{Method specificity}

The method specificity was investigated by injecting blank mobile phase before the start of each run. The blank standards were used to control for any interfering peak that elutes at the same retention time of ciclosporin. The interfering peaks might arise from the mobile phase or the extraction process.

\section{Coefficient of variation}

Each ciclosporin calibration standard peak area was divided by its concentration in order to calculate the slope of the standard curve. The average and the standard deviation of the slope of all calibration standards were then calculated. Then the intra-day coefficient of variation $(\mathrm{CV})$ of this calibration line was calculated by dividing the standard deviation by the average (of at least three samples) and multiplied by 100 .

\section{Inaccuracy}

The inaccuracy of the assay was determined by measuring the difference between actual (hypothetical) and the measured concentration of each ciclosporin calibration standard. The concentration difference was then divided by the actual concentration and multiplied by 100 .

\section{HPLC system carry over}

The HPLC system carryover was checked by running blank samples between actual samples. The blank sample was checked for the presence of any carried over ciclosporin. Calibration standards were also randomised and the calibration curve linearity was then checked in order to detect any carryover.

\section{Dissolution extraction recovery}

The recovery of the volume was calculated by dividing the actual volume over the total volume then multiplied by concentration.

\section{Stability}

Freeze thaw stability was done for three ciclosporin calibration standards stored at $-20^{\circ} \mathrm{C}$, thawed and re-frozen every week for three weeks.

\section{Statistical analysis and graphic presentation}

The graphic presentations and the statistical analyses were done using Excel 2010 for Windows version, 14.0.6112.500 (32-bit) and Minitab version, 16.

\section{Results}

\section{Optimisation of the UV detector for ciclosporin measurement}

The highest absorbance was between 205 and $215 \mathrm{~nm}$. Based on this result, the maximum absorbance at $210 \mathrm{~nm}$ was used to detect ciclosporin in all subsequent experiments.

\section{Dissolution test}

The results of the dissolution test showed that the average rupture times for ciclosporin capsules of generic $\mathrm{C}$, brand $\mathrm{T}$, brand $\mathrm{J}$, brand $\mathrm{E}$, generic $\mathrm{I}$, brand $\mathrm{P}$ and brand $\mathrm{S}$ were (mean $\pm \mathrm{SD}$ ) $1.56 \pm 0.02,5.07$ $\pm 0.02,5.11 \pm 0.01,5.29 \pm 0.02,5.34 \pm 0.03,5.37 \pm 0.02$ and $5.43 \pm$ $0.02 \mathrm{~min}$ respectively. The capsule rupture was determined through the dissolution vessel by visual observation of the capsule shell and/ or by the release of capsule content. A sample was tested using HPLC before putting the capsule into the vessel to ensure no ciclosporin contamination of the medium. The HPLC chromatogram shows that there was no ciclosporin peak (Figure 2). This confirms the absence of ciclosporin in the medium. Rupturing time was calculated for each capsule by using a stop watch. In this study, all the capsules met the USP requirements, rupturing within $15 \mathrm{~min}$ (Table 1 ).

\section{Calibration and linearity}

The separation of ciclosporin was achieved using the method and a typical ciclosporin chromatogram is shown in Figures 3 and 4. A

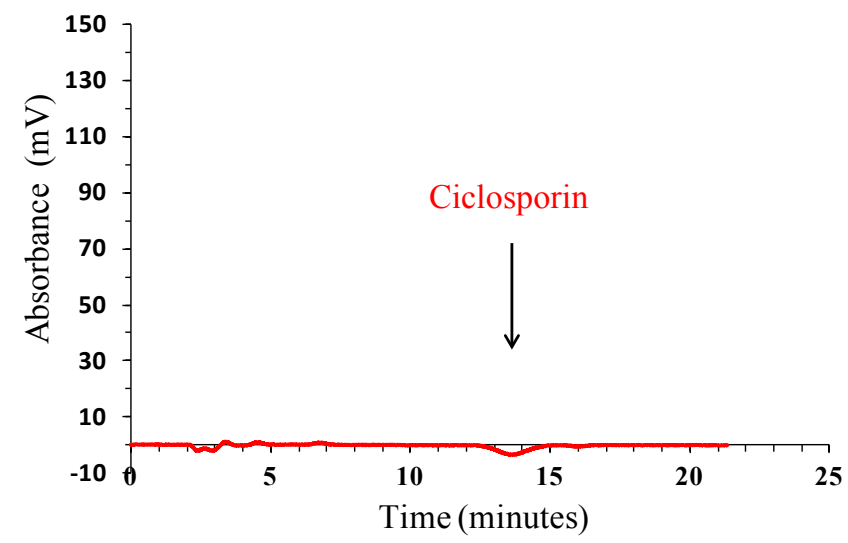

Figure 2: Chromatogram to show there is no peak before putting the ciclosporin capsule in the dissolution tester. 
Citation: Aljohani B, Alotaibi F, Ghazaly E, Jaber JA, Perrett D, et al. (2017) Development and Validation of A HPLC-UV Method for Dissolution Testing of Ciclosporin: Its Application to The Measurement of Brand and Generic Versions from Different Countries. J Bioequiv Availab 9: 509-515. doi: 10.4172/jbb.1000354

\begin{tabular}{|c|c|}
\hline Ciclosporin Capsule & Average Rupture Time $(\mathbf{m i n}) \pm$ SD \\
\hline Generic C & $1.56 \pm 0.02$ \\
\hline Brand T & $5.07 \pm 0.02$ \\
\hline Brand J & $5.11 \pm 0.01$ \\
\hline Brand E & $5.29 \pm 0.02$ \\
\hline Generic I & $5.34 \pm 0.03$ \\
\hline Brand P & $5.37 \pm 0.02$ \\
\hline Brand S & $5.43 \pm 0.02$ \\
\hline
\end{tabular}

Table 1: Average rupture time for ciclosporin capsules $(n=4)$.

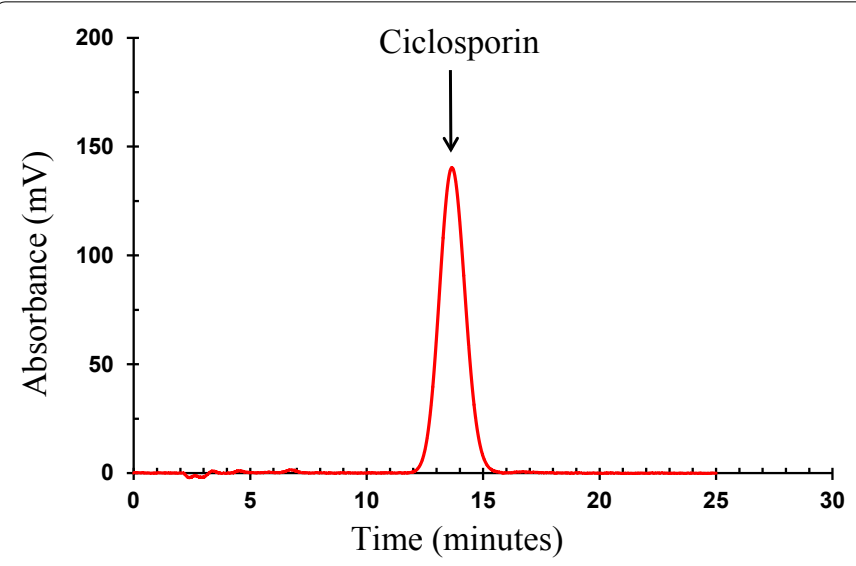

Figure 3: Chromatogram obtained from a sample solution contains $200 \mu \mathrm{g} /$ $\mathrm{mL}$ ciclosporin.

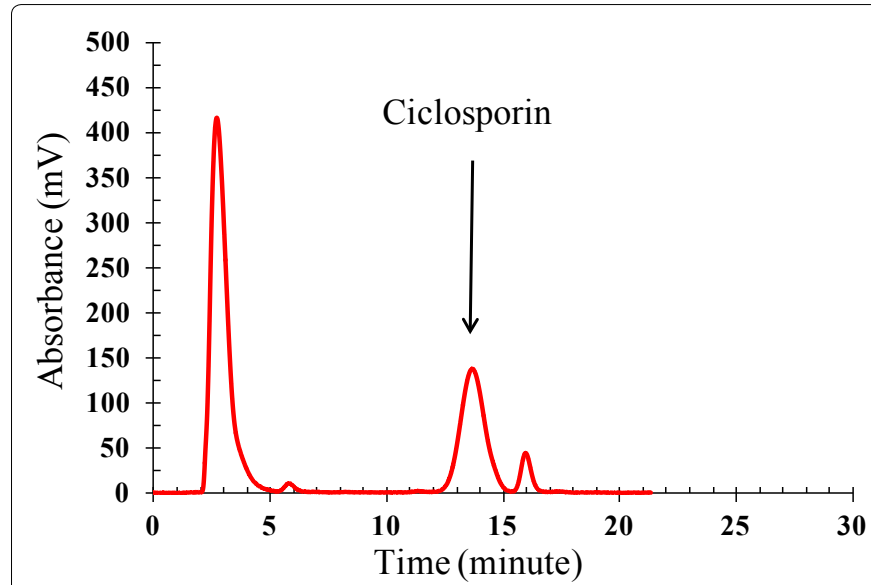

Figure 4: Chromatogram obtained at 90 minutes sampling from a dissolution tester.

symmetrical peak shape with a retention time of 13.8 min corresponds to ciclosporin retention time. The peak areas of the ciclosporin standards were $46,92.3,183,275,367,459,688,916 \mathrm{mVmin}$ for $0.1,0.2$, $0.4,0.6,0.8,1.0,1.5$, and $2 \mathrm{mg} / \mathrm{mL}$ respectively. The linear regression (R2) was 1.00, regression residuals less than $\pm 5 \%$ (Figure 4). In Figure 5 show linear regression residuals for ciclosporin standards, and Figure 6, we can see a standard curve for ciclosporin analysis using the HPLC system.

\section{Method sensitivity}

On seven different days, the mean concentration measured of the lowest standard $(0.1 \mathrm{mg} / \mathrm{mL})$ was $0.09 \pm 0.01(\mathrm{mg} / \mathrm{mL})$ with $\mathrm{CV}$ of

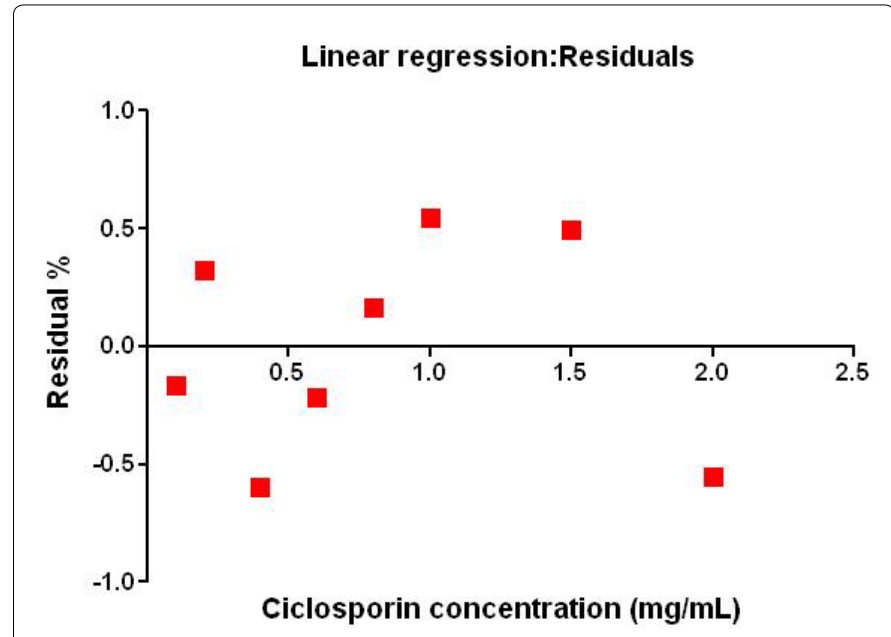

Figure 5: Linear regression residuals for ciclosporin standards, less than $5 \%$.

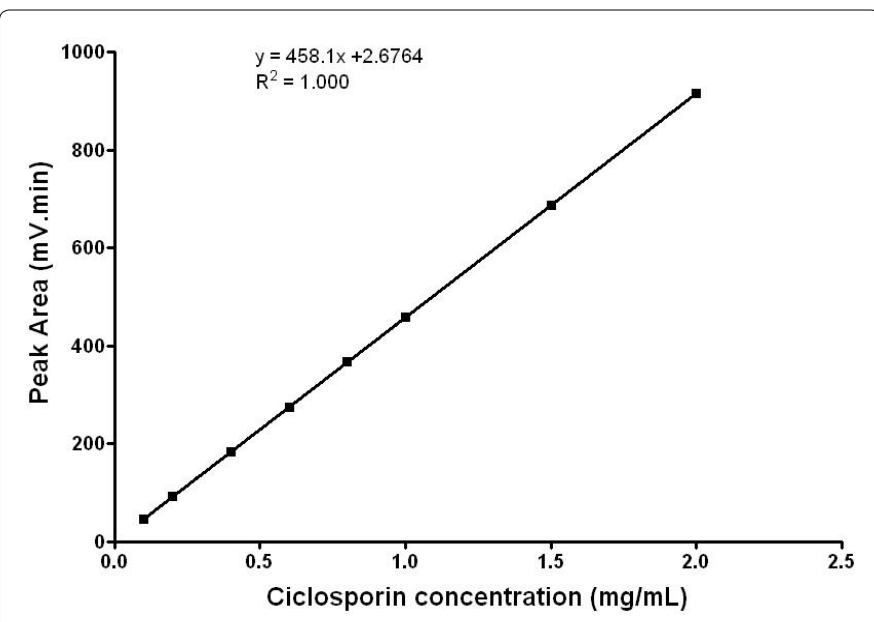

Figure 6: Standard curve for ciclosporin analysis using the HPLC system.

$11.84 \%$. The highest standard was $2.01 \pm 0.08(\mathrm{mg} / \mathrm{mL})$ with a CV of $4.22 \%$ (Table 2).

\section{Method specificity and carry over}

The method for measuring ciclosporin was specific. Blank mobile phase samples were used before, between and after each run. No significant interfering peaks and no presence of any carried over ciclosporin at the migration time of ciclosporin samples.

\section{Precision}

Inter-day variability: Ciclosporin standards at $0.1,0.2,0.4,0.6,0.8$, $1,1.5$, and $2 \mathrm{mg}$ were injected into the HPLC system. Table 3 shows the hypothetical and measured concentrations by HPLC analysis for these samples over six different days along with the average, standard deviation, and the coefficient of variation percentage.

Intra-day variability: Ciclosporin standards at $0.1,0.2,0.4,0.6$, $0.8,1,1.5$, and $2 \mathrm{mg}$ were injected into the HPLC system on the same day. Table 4 shows the actual and measured concentrations for these samples, average, standard deviation, and the correlation of variation percentage. 
Citation: Aljohani B, Alotaibi F, Ghazaly E, Jaber JA, Perrett D, et al. (2017) Development and Validation of A HPLC-UV Method for Dissolution Testing of Ciclosporin: Its Application to The Measurement of Brand and Generic Versions from Different Countries. J Bioequiv Availab 9: 509-515. doi: 10.4172/jbb.1000354

Inaccuracy: The inaccuracy of the method was measured by calculating the difference between the actual and measured concentration of each ciclosporin calibration standard (Table 5).

The first day the inaccuracy of the 3 lowest concentration was above acceptable level due to unknown reason however in subsequent 6 experiments the inaccuracies were within acceptable range (less than $15 \%)$.

Drug recovery (from capsules): This was done in order to confirm that the dissolution test successfully recovered all the capsule content after 60 and $90 \mathrm{~min}$. Maximal recovery $(99 \pm 0.4 \%)$ was after $60 \mathrm{~min}$. Recovery after 90 min was $100 \pm 0.5 \%$ (Table 6).

\section{Stability}

This test was done to check the stability of ciclosporin standards in stock solutions. Ciclosporin standards were stable for the whole period of the experiment. Two different concentrations of 0.4 and $0.6 \mathrm{mg}$ from

\begin{tabular}{|c|c|c|}
\hline Days & $\begin{array}{c}\text { Measured concentration of } \\
\text { lowest standard }(\mathbf{0 . 1} \mathbf{~ m g} / \mathbf{m L})\end{array}$ & $\begin{array}{c}\text { Measured concentration of } \\
\text { highest standard } \mathbf{2} \mathbf{~ m g} / \mathbf{m L})\end{array}$ \\
\hline D1 & 0.07 & 2.21 \\
\hline D2 & 0.1 & 1.97 \\
\hline D3 & 0.1 & 1.99 \\
\hline D4 & 0.1 & 2 \\
\hline D5 & 0.1 & 1.99 \\
\hline D6 & 0.1 & 2 \\
\hline D7 & 0.1 & 1.97 \\
\hline Average & 0.09 & 2.01 \\
\hline I SD & 0.01 & 0.08 \\
\hline
\end{tabular}

Table 2: The concentration of low and high standards on different days.

\begin{tabular}{|c|c|c|c|c|c|c|}
\hline $\begin{array}{c}\text { Concentration } \\
(\mathbf{m g} / \mathbf{m L})\end{array}$ & $\begin{array}{c}\text { Day1 } \\
(\mathbf{m g} / \mathbf{m L})\end{array}$ & $\begin{array}{c}\text { Day2 } \\
(\mathbf{m g} / \mathbf{m L})\end{array}$ & $\begin{array}{c}\text { Day3 } \\
(\mathbf{m g} / \mathbf{m L})\end{array}$ & $\begin{array}{c}\text { Day4 } \\
(\mathbf{m g} / \mathbf{m L})\end{array}$ & $\begin{array}{c}\text { Day5 } \\
(\mathbf{m g} / \mathbf{m L})\end{array}$ & $\begin{array}{c}\text { Day6 } \\
(\mathbf{m g} / \mathbf{m L})\end{array}$ \\
\hline 0.1 & 0.1 & 0.09 & 0.1 & 0.09 & 0.1 & 0.1 \\
\hline 0.2 & 0.2 & 0.2 & 0.21 & 0.2 & 0.21 & 0.2 \\
\hline 0.4 & 0.38 & 0.39 & 0.4 & 0.39 & 0.4 & 0.38 \\
\hline 0.6 & 0.62 & 0.61 & 0.57 & 0.61 & 0.57 & 0.62 \\
\hline 0.8 & 0.82 & 0.81 & 0.82 & 0.81 & 0.82 & 0.82 \\
\hline 1 & 1.01 & 1.01 & 1.02 & 1.01 & 1.02 & 1.01 \\
\hline 1.5 & 1.51 & 1.49 & 1.46 & 1.49 & 1.46 & 1.51 \\
\hline 2 & 1.97 & 1.98 & 2 & 1.98 & 2 & 1.97 \\
\hline
\end{tabular}

Inter-day variability was acceptable for ciclosporin across the standard range $(<5 \%)$.

Table 3: The average, standard deviation $( \pm S D)$ and the coefficient of variation (CV) for the inter-day variability for ciclosporin assay standards at $0.1,0.2,0.4,0.6$ $0.8,1,1.5$, and $2 \mathrm{mg} / \mathrm{mL}$.

\begin{tabular}{|c|c|c|c|c|c|}
\hline $\begin{array}{c}\text { Concentration } \\
(\mathbf{m g} / \mathbf{m L})\end{array}$ & $\begin{array}{c}\text { Concentration } \\
(\mathbf{m g} / \mathbf{m L})\end{array}$ & $\begin{array}{c}\text { Concentration } \\
(\mathbf{m g} / \mathbf{m L})\end{array}$ & Mean & $\mathbf{\pm S D}$ & $\begin{array}{c}\mathbf{C V} \% \\
\text { intra-day }\end{array}$ \\
\hline 0.1 & 0.09 & 0.10 & 0.10 & 0.0022 & 2.22 \\
\hline 0.2 & 0.20 & 0.21 & 0.20 & 0.0074 & 3.64 \\
\hline 0.4 & 0.39 & 0.40 & 0.40 & 0.0092 & 2.30 \\
\hline 0.6 & 0.61 & 0.57 & 0.59 & 0.0241 & 4.05 \\
\hline 0.8 & 0.81 & 0.82 & 0.82 & 0.0042 & 0.51 \\
\hline 1 & 1.01 & 1.02 & 1.02 & 0.0091 & 0.89 \\
\hline 1.5 & 1.49 & 1.46 & 1.48 & 0.0161 & 1.08 \\
\hline 2 & 1.98 & 2.00 & 1.99 & 0.0102 & 0.51 \\
\hline
\end{tabular}

Intra-day variability was acceptable for ciclosporin across the standard range $(<4 \%)$.

Table 4: The average, standard deviation $( \pm S D)$ and the coefficient of variation (CV) for the intra-day variability for ciclosporin assay standard at $0.1,0.2,0.4,0.6$, $0.8,1,1.5$, and $2 \mathrm{mg} / \mathrm{mL}$. day 2, 4, and 6 were measured (Table 7). The ciclosporin standards were stable for freeze-thaw cycles. Average measured concentration for 3 cycles of 0.4 and $0.6 \mathrm{mg}$ of ciclosporin was 0.39 and 0.61 respectively. The CV\% of 0.4 and $0.6 \mathrm{mg}$ of ciclosporin standards were less than $3 \%$. The inaccuracy of measured concentration was less than $\pm 3 \%$.

\section{Application of the assay}

This method was successfully applied to measure the actual concentration in each ciclosporin product using HPLC analysis. Sampling time was done on six different intervals in order to check for ciclosporin release from capsules. All brands (T, S, E, J, P) and one generic $(\mathrm{C})$ showed more than $80 \%$ of labelled amount in ciclosporin capsules after $90 \mathrm{~min}$ of the dissolution test giving $100 \pm 0.05,90 \pm 0.07$, $81 \pm 0.04,83 \pm 0.05,90 \pm 0.03$, and $91 \pm 0.01 \%( \pm S D)$ respectively. One generic (I), showed less than the minimum percentage of labelled amount $69 \pm 0.08 \%$. Relative to the brand $(\mathrm{T})$, statistical analysis showed significant differences $(p<0.0001)$ of the mean percentage content between brand and generic, the confidence interval $95 \%$ range for the brands (S, E, J, P) were (80.1-101.8), (72.2-91.8), (73.4-93.3), (80.2-101.9), respectively, and (80.3-102.1), (61.3-77.9), for the generic (C) and (I) respectively (Tables 8 and 9).

The average percentage of ciclosporin mass amount, standard deviation, the coefficient of variation and $95 \%$ CI based on reference capsule (T) $100 \%$ mass amount, $(n=4)$.

\begin{tabular}{|c|c|c|c|c|c|c|c|c|}
\hline $\begin{array}{c}\text { Concentration } \\
(\mathbf{m g} / \mathbf{m L})\end{array}$ & Day1 & Day2 & Day3 & Day4 & Day5 & Day6 & Average & $\mathbf{\pm S D}$ \\
\hline 0.1 & -32.69 & 0.19 & 2.98 & 0.19 & 2.98 & 1.7 & -4.1 & 14 \\
\hline 0.2 & -29.27 & 0.12 & 5.41 & 0.12 & 5.41 & 1.15 & -2.83 & 13 \\
\hline 0.4 & -23.97 & 0.9 & 2.38 & 0.9 & 2.38 & 4.66 & -2.12 & 11 \\
\hline 0.6 & 11.65 & 1.93 & 3.75 & 1.93 & 3.75 & 3.38 & 4.4 & 4 \\
\hline 0.8 & 2.24 & 2.26 & 3.01 & 2.26 & 3.01 & 2.52 & 2.55 & 0 \\
\hline 1 & -1.96 & 1.64 & 2.94 & 1.64 & 2.94 & 1.96 & 1.52 & 2 \\
\hline 1.5 & -18.14 & 0.53 & 2.05 & 0.53 & 2.05 & 0.69 & -2.04 & 8 \\
\hline 2 & 10.62 & 0.61 & 0.11 & 0.61 & 0.11 & 1.41 & 2.24 & 4 \\
\hline
\end{tabular}

Table 5: Inaccuracy of the assay was $<4 \%$ of the true value at standard curve concentrations range from 0.1 to $2 \mathrm{mg} / \mathrm{mL}$ of ciclosporin.

\begin{tabular}{|c|c|c|}
\hline \multicolumn{3}{|c|}{ Recovery Average } \\
\hline Ciclosporin & 60 min & 90 min \\
\hline Brand T & $99 \pm 0.04 \%$ & $100 \pm 0.05 \%$ \\
\hline Brand P & $91 \pm 0.03 \%$ & $90 \pm 0.03 \%$ \\
\hline Brand S & $88 \pm 0.04 \%$ & $90 \pm 0.07 \%$ \\
\hline Generic C & $86 \pm 0.05 \%$ & $91 \pm 0.01 \%$ \\
\hline Brand J & $84 \pm 0.02 \%$ & $83 \pm 0.05 \%$ \\
\hline Brand E & $76 \pm 0.05 \%$ & $81 \pm 0.04 \%$ \\
\hline Generic I & $69 \pm 0.04 \%$ & $69 \pm 0.08 \%$ \\
\hline
\end{tabular}

Table 6: The average recovery percentage of ciclosporin mass amount after 60 and 90 min of the dissolution test $(n=4)$.

\begin{tabular}{|c|c|c|c|c|c|c|}
\hline $\begin{array}{c}\text { Ciclosporin } \\
\text { Concentration } \mathbf{( m g /} / \\
\mathbf{m L})\end{array}$ & $\begin{array}{c}\text { Day 2 } \\
(\mathbf{m g} / \mathbf{m L})\end{array}$ & $\begin{array}{c}\text { Day 4 } \\
(\mathbf{m g} / \mathbf{m L})\end{array}$ & $\begin{array}{c}\text { Day 6 } \\
(\mathbf{m g} / \mathbf{m L})\end{array}$ & Average & $\mathbf{\pm S D}$ & $\mathbf{C V} \%$ \\
\hline $\mathbf{0 . 4}$ & 0.39 & 0.39 & 0.38 & 0.39 & 0.009 & 2.22 \\
\hline $\mathbf{0 . 6}$ & 0.61 & 0.61 & 0.62 & 0.61 & 0.005 & 0.82 \\
\hline Inaccuracy & Day 2 & Day 4 & Day 6 & Average & \pm SD & \\
\hline $\mathbf{0 . 4}$ & 0.9 & 0.9 & 4.66 & 2.15 & 2.173 & \\
\hline $\mathbf{0 . 6}$ & 1.93 & 1.93 & 3.38 & 2.41 & 0.839 & \\
\hline
\end{tabular}

Table 7: The average concentration ( \pm SD) and coefficient of variation (CV) and inaccuracy of ciclosporin stability in stock solution for day 2,4 and 6 . 
Citation: Aljohani B, Alotaibi F, Ghazaly E, Jaber JA, Perrett D, et al. (2017) Development and Validation of A HPLC-UV Method for Dissolution Testing of Ciclosporin: Its Application to The Measurement of Brand and Generic Versions from Different Countries. J Bioequiv Availab 9: 509-515. doi: 10.4172/jbb.1000354

\begin{tabular}{|c|c|c|c|c|c|c|c|c|}
\hline \multirow[t]{2}{*}{ Drug Name } & \multirow[t]{2}{*}{ Country of Origin } & \multirow{2}{*}{$\begin{array}{c}\text { Average weight } \\
\text { (g), } n=4\end{array}$} & \multicolumn{6}{|c|}{ Sampling time $(\min )$ and Average content $\%, n=4$} \\
\hline & & & $5 \mathrm{~min}$ & $10 \mathrm{~min}$ & $15 \mathrm{~min}$ & $30 \mathrm{~min}$ & $60 \mathrm{~min}$ & $90 \mathrm{~min}$ \\
\hline Neoral $\mathrm{Q}^{\otimes^{*}}$ & Turkey & 1.5 & $6.70 \%$ & $55.80 \%$ & $98.30 \%$ & $98.60 \%$ & $98.80 \%$ & $100.00 \%$ \\
\hline Neoral $^{\Theta^{*}}$ & Saudi & 1.51 & $0.40 \%$ & $57.80 \%$ & $85.00 \%$ & $91.90 \%$ & $88.40 \%$ & $90.40 \%$ \\
\hline Neoral $^{\circledR}$ & Jordan & 1.67 & $3.20 \%$ & $65.30 \%$ & $77.60 \%$ & $80.50 \%$ & $84.20 \%$ & $82.80 \%$ \\
\hline Neoral $^{\circledR}$ & Egypt & 1.69 & $3.10 \%$ & $13.50 \%$ & $55.70 \%$ & $74.80 \%$ & $76.20 \%$ & $81.40 \%$ \\
\hline Neoral $^{\otimes^{*}}$ & Pakistan & 1.5 & $6.90 \%$ & $79.20 \%$ & $93.30 \%$ & $89.30 \%$ & $91.30 \%$ & $90.40 \%$ \\
\hline Generic C ${ }^{*}$ & Colombia & 1.32 & $85.00 \%$ & $94.70 \%$ & $88.00 \%$ & $89.50 \%$ & $86.10 \%$ & $90.50 \%$ \\
\hline Generic I* & India & 1.6 & $4.60 \%$ & $47.80 \%$ & $72.00 \%$ & $65.70 \%$ & $68.90 \%$ & $69.30 \%$ \\
\hline
\end{tabular}

${ }^{*}$ Ciclosporin $100 \mathrm{mg}$ capsules. Jordan and Egypt capsules contain 50.

Table 8: Shows the average percentage of ciclosporin mass amount at different time intervals, reference capsule (Turkey) showed $100 \%$ mass amount after 90 min, ( $n=4$ ).

\begin{tabular}{|l|c|c|c|c|c|}
\hline \multicolumn{1}{|c|}{$\begin{array}{c}\text { Ciclosporin } \\
\text { Capsule }\end{array}$} & $\mathbf{N}$ & \% of mass amount at 90 $\mathbf{~ i n ~} \mathbf{( m g / m L )}$ & $\mathbf{\pm ~ S D}$ & $\mathbf{C V ~ ( \% )}$ & $\mathbf{9 5 \%}$ Confidence Interval \\
\hline Generic I $(100 \mathrm{mg})$ & 4 & 69.3 & 7.6 & 11 & $(61.3-77.9)$ \\
\hline Brand E $(50 \mathrm{mg})$ & 4 & 81.4 & 3.6 & 4 & $(72.2-91.8)$ \\
\hline Brand J $(50 \mathrm{mg})$ & 4 & 82.8 & 4.7 & 6 & $(73.4-93.3)$ \\
\hline Brand S $(100 \mathrm{mg})$ & 4 & 90.4 & 6.9 & 8 & $(80.1-101.8)$ \\
\hline Brand P $(100 \mathrm{mg})$ & 4 & 90.4 & 3.3 & 4 & $(80.2-101.9)$ \\
\hline Generic C $(100 \mathrm{mg})$ & 4 & 90.5 & 1.2 & 1 & $(80.3-102.1)$ \\
\hline
\end{tabular}

Table 9: Average percentage content of ciclosporin in capsules.

\section{Discussion}

Ciclosporin is an important immunosuppressant agent. In recent years, many studies have questioned the use of generic substitutes, especially when considering those that are narrow therapeutic index drugs (NTIDs).

In this work, the aim was to develop, validate and apply a dissolution test for ciclosporin in capsules using an HPLC method and then to compare brand medications to the generic or copy products. Moreover, the detection of contaminants and the source of impurities in these products are essential to understanding.

A sensitive and specific HPLC-UV method was developed to detect and subsequently quantitate the ciclosporin active base in capsules. Dissolution testing of the capsules was done as specified in the US pharmacopeia. Analytes were isocratically eluted at $0.7 \mathrm{~mL} / \mathrm{min}$ with acetonitrile and water $(70: 30 \% \mathrm{v} / \mathrm{v})$ and $0.03 \% \mathrm{v} / \mathrm{v}$ trifluoroacetic acid over the $25 \mathrm{~min}$ runtime. The hydrocarbon chain forming the hydrophobic phase is usually a hydrocarbon of eighteen (C18), eight (C8) or four (C4) carbons. Peptides need longer hydrophobic chain lengths to be resolved [17]. Various C18 columns were tested to get a good separation of ciclosporin by the HPLC method. The ACE 5 column showed the best results. All subsequent development was undertaken on this column. Although the USP recommends that the column should be heated to $80^{\circ} \mathrm{C}$, at $50^{\circ} \mathrm{C}$ we achieved the necessary sensitivity and separation.

In addition, the dissolution profile revealed that all the ciclosporin capsules used in these investigations complied with US Pharmacopeia, rupturing within $15 \mathrm{~min}$ [13].

The standard curve, when fitted using least square linear regression, was linear $\left(r^{2}=0.9998\right)$. The separation of ciclosporin was successful at $13.8 \mathrm{~min}$ retention time. Detection of ciclosporin at low and high concentration was reproducible. The lower limit of quantification was $0.1 \mathrm{mg} / \mathrm{mL}$, higher limit of quantification was $2 \mathrm{mg} / \mathrm{mL}$ and the method was sensitive with CV\% of 4.2 and $11.8 \%$ at high and low quantitation limits respectively.

The within day variability was mostly less than $4 \%$. The between day variability of the standards was within an acceptable range mostly less than $5 \%$.

The method was accurate. The inaccuracy of the assay was within $<4 \%$. However, on the first day, the inaccuracy of the three lowest concentrations was higher than the acceptable range (15\%) due to unknown reason. There was no system carry over for ciclosporin. Blank samples were run between the actual samples without detection of any carried over of ciclosporin.

Different concentrations at 0.4 and $0.6 \mathrm{mg}$ used to check the stability. $\mathrm{CV}$ was less than $3 \%$ and the inaccuracy of measured concentration within $\pm 3 \%$.

The application of the assay was successful. The Turkey brand was the best brand in terms of the content of the active ingredient with 100 $\pm 0.05 \%$. The Indian brand had only $69 \pm 0.08 \%$. There were one or more impurities in all capsules. There are some discrepancies in the dissolution methods between the FDA and the USP. The FDA suggests using a $\mathrm{L}$ of $0.1 \mathrm{~N} \mathrm{HCl}$ containing $4 \mathrm{mg}$ of $\mathrm{N}, \mathrm{N}$-dimethydodecylamine$\mathrm{N}$-oxide per $\mathrm{mL}$ with $75 \mathrm{rpm}$. But the USP in 2008 recommends the use of $500 \mathrm{~mL}$ water with $50 \mathrm{rpm}$.

In the USP there is no mention of the times at which the sampling should be taken apart from the fact that they ask us to test at $90 \mathrm{~min}$ where there should be more than $80 \%$ of the content. In this study, we did 5, 10, 15, 30, 60 and $90 \mathrm{~min}$.

The results of this study are surprised that the content is much less than $80 \%$ in some of the capsules and are not $100 \%$ in all the brand capsules either. This raise concerns over the manufacturing standards and the quality control measures employed even within the same brand manufactured in different countries. In the literature, The Danish medicine agencies suggested that the generic substitution should no longer be used for ciclosporin following a reassessment [18]. The contents of one of the ciclosporin capsules we reported in this study as an agreement with those found by other researchers [19], where they detected only $68 \%$ of the labelled concentration in one of the generic capsules. 
Citation: Aljohani B, Alotaibi F, Ghazaly E, Jaber JA, Perrett D, et al. (2017) Development and Validation of A HPLC-UV Method for Dissolution Testing of Ciclosporin: Its Application to The Measurement of Brand and Generic Versions from Different Countries. J Bioequiv Availab 9: 509-515. doi: 10.4172/jbb.1000354

\section{Conclusion}

This study represents a simple, rapid, specific and sensitive HPLC method for the determination of an immunosuppressive drug ciclosporin. This method was used successfully in determination of ciclosporin mass amount in brand versus generic capsules. Overall, switching among and between brands and generic ciclosporin can lead to undesirable effects.

\section{References}

1. The national archives (2009) Drug and Safety Update. MHRA 3.

2. Golabi N, Tajerzadeh $\mathrm{H}$, Ghassempour A (2003) A rapid and selective LC method for simultaneous determination of cyclosporin a and its major metabolite (AM1) in human serum at room temperature. Talanta 59: 1089-1094.

3. Tribe H T (1998) The discovery and development of cyclosporin. Mycologist 12: $20-22$.

4. Hauer B, Meinzer A, Posanski U, Richter F (1994) Pharmaceutical compositions comprising cyclosporins, U.S. Patent No. 5,342,625. Washington, DC: U.S. Patent and Trademark Office.

5. Allison AC, Eugui EM (2000) Mycophenolate mofetil and its mechanisms of action. Immunopharmacology 47: 85-118.

6. Thomas K, Koelwel C, Machei U, Farber L, Gopferich A (2005) Three generations of cyclosporine a formulations: an in vitro comparison. Drug Dev Ind Pharm 31: 357-366.

7. Food and Drug Administration (2011) NEORAL ${ }^{\circledR}$ soft gelatin capsules (cyclosporine capsules, USP) modified. Novartis.

8. FDA (2011) Novartis Pharmaceuticals Corporation: Report. Novartis.

9. Burckart GJ, Jain A, Diven W, Venkataramanan R, Starzl TE (1990) Cyclosporine measurement by FPIA, PC-RIA, and HPLC following liver transplantation. Transplant Proc 22: 1319
10. Chimalakonda AP, Shah RB, Mehvar R (2002) High-performance liquid chromatographic analysis of cyclosporin $A$ in rat blood and liver using a commercially available internal standard. J Chromatogr B Analyt Techno Biomed Life Sci 772: 107.

11. Shaw LM, Holt DW, Keown P, Venkataramanan R, Yatscoff RW, et al (1999) Current opinions on therapeutic drug monitoring of immunosuppressive drugs. Clinical therapeutics 21: 1632-1652.

12. Aziz F, Gupta A, Khan MF (2010) Development and Validation of a RP-HPLC Method for Determination of Cyclosporine in Capsule. Indian J Pharm Sci 72: 252-755.

13. United States pharmacopeia convention (2008) United States Pharmacopeia monographs: cyclosporine. USP, 12601 Twinbrook Parkway, Rockville, MD 20852.

14. Ghareeb M, Akhlaghi F (2015) Alternative matrices for therapeutic drug monitoring of immunosuppressive agents using LC-MS/MS. Bioanalysis 7 : 1037-1058.

15. Mika A, Stepnowski P (2016) Current methods of the analysis of immunosuppressive agents in clinical materials: A review. J Pharm Biomed Anal 127: 207-231.

16. Sharma P, Varma MV, Chawla HP, Panchagnula R (2005) Relationship between lipophilicity of BCS class III and IV drugs and the functional activity of peroral absorption enhancers. Farmaco 60: 870-873.

17. Carr D (2002) The handbook of analysis and purification of peptides and proteins by reversed-phase HPLC. Hesperia, CA, USA: Grace Vydac.

18. Heisterberg J (2011) Generic substitution terminated for oral medicines containing cyclosporine or tacrolimus. DMA.

19. Bonifacio FN, Giocanti M, Reynier JP, Lacarelle B, Nicolay A(2009) Development and validation of HPLC method for the determination of Cyclosporin $A$ and its impurities in Neoral ${ }^{\circledR}$ capsules and its generic versions. J Pharm Biomed Anal 49: 540 . 